\title{
Microstructure of Zirconia-Based Sol-Gel Glasses Studied by SANS
}

\author{
V. Ryukhtin ${ }^{a, *}, \mathrm{P} . \mathrm{Strunz}^{a}, \mathrm{G} \cdot \mathrm{Kopitsa}^{b}, \mathrm{~K}$ Ezdakova $^{b}, \mathrm{~N} . \mathrm{Gubanova}^{b}, \mathrm{~V} . \mathrm{Ivanov}^{c, d}$,

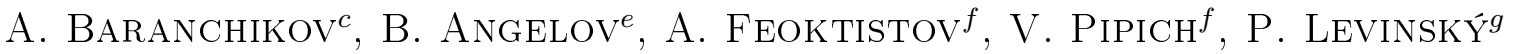 \\ ${ }^{a}$ Nuclear Physics Institute ASCR v.v.i., Řž near Prague, 25068, Czech Republic \\ ${ }^{b}$ Petersburg Nuclear Physics Institute NRC KI, Orlova roscha 1, Gatchina 188300, Russia \\ ${ }^{c}$ Kurnakov Institute of General and Inorganic Chemistry of RAS, Moscow 119991, Russia \\ ${ }^{d}$ National Research Tomsk State University, Lenin ave., 36, Tomsk, 634050, Russia \\ ${ }^{e}$ Institute of Macromolecular Chemistry ASCR, v.v.i., Heyrovského nám. 2, Prague, 16200, Czech Republic \\ ${ }^{f}$ Jülich Centre for Neutron Science JCNS-FRM II, Lichtenbergstr. 1, Garching, 85747, Germany \\ ${ }^{g}$ Faculty of Nuclear Sciences and Physical Engineering, Czech Technical University, Prague, 16600, Czech Republic
}

\begin{abstract}
Zirconia-based bulk glasses were prepared for the first time by sol-gel method. Such materials are very promising for application as photochromic devices, catalytic systems, chemical sensors, lasers and other nonlinear optics devices. Obtained transparent and semi-transparent materials were studied by small and ultra-small angle neutron scattering (SANS and USANS) methods. As evidenced by SANS, morphology of zirconia glasses is very sensitive to parameters of sol-gel synthesis, e.g. temperature and concentration of reactants. SANS data correlates rather well with surface porosity data. Increasing water concentration in reaction mixtures containing zirconium propylate leads to a significant increase in fractal cluster size, while decrease of the temperature results in an increase of the fractal dimension. The obtained results indicate that parameters of the microstructure and consequently physical properties of zirconia glasses can be effectively controlled by parameters of synthesis.
\end{abstract}

DOI: 10.12693/APhysPolA.128.582

PACS: $61.05 . f g, 81.20 . \mathrm{Fw}, 81.05 . \mathrm{Kf}, 61.43 . \mathrm{Fs}$

\section{Introduction}

Transparent sol-gel glasses are widely used in photochromic devices, e.g. as chemical sensors or catalyzers, due to their low cost and good optical properties [1]. In order to overcome some application restrictions, an increasing interest is paid to zirconia [2] as a promising glass-forming component in the last decades. Synthesis of glassy materials using the sol-gel method brings some advantages in comparison with the conventional melting or sintering. Above all, it allows fine tuning of physical properties of glasses by controlling sol-gel synthesis parameters affecting structure of these materials at the nanoscale level.

Among other methods, small-angle neutron scattering (SANS) has been proved to be very effective for investigation of nanostructures in bulk of solid materials since 1970's (see e.g. [3-6]). In some cases, SANS data interpretation is not straightforward - in contrast to other complementary and cheaper techniques such as electron microscopy (SEM, TEM), gas adsorption/desorption (BET) etc. On the other hand, SANS has several inherent advantages including excellent statistics and easy sample preparation procedures. In this work, three SANS instruments were used for a microstructural study of zirconia-based sol-gel glasses in

* corresponding author; e-mail: ryukhtin@ujf.cas.cz a wide size range (from $\mathrm{nm}$ to $\mu \mathrm{m}$ ) aiming at determination of microstructure dependence on sol-gel synthesis conditions.

\section{Synthesis of the samples}

Solution of zirconium propylate (70 wt\% in npropanol) was mixed with concentrated nitric acid (70 wt\%) and isopropanol (87.9 wt\%). Pure water was added as hydrolyzing agent in three molar ratios to $\mathrm{Zr}$ (1: $10.58 ; 1: 5.29 ; 1: 2.65)$. Resulted mixtures were aged at either $20^{\circ} \mathrm{C}$ or $0^{\circ} \mathrm{C}$. The obtained glassy samples are listed in the Table. Detailed description of sample preparation procedure can be found elsewhere [7]. Images taken by Carl Zeiss $\mathrm{N}$ Vision 40 scanning electron microscope (SEM) instrument of the untreated samples with highest and lowest $\mathrm{H}_{2} \mathrm{O}$ ratio in initial mixtures are shown in Fig. 1.

\section{SANS analysis}

SANS measurements were carried out at KWS-1, KWS-3 (FRM-II reactor, Garching, Germany) and MAUD (CANAM, NPI, Rež, Czech Republic) facilities. Joint use of these setups allows us to cover wide range of momentum transfers magnitude $Q$ from $2 \times 10^{-4} \AA^{-1}$ (MAUD) [8, 9] to $0.43 \AA^{-1}$ (KWS-1) [10]. Resulting scattering curves (Fig. 2) show power law dependence $\approx Q^{-D}$ for low $Q$ values. For samples with lower amount of water $\left(1 \mathrm{~V} / 2 \mathrm{~V}\left(\mathrm{H}_{2} \mathrm{O}\right)(-\mathrm{ice})\right)$, there is a notable increase in intensity in the region corresponding to the smallest pores (down to few nanometers), which are also visible in SEM images (Fig. 1). The power law behavior of SANS curves with $D \neq 4$ at low $Q$ can be explained by a fractal 

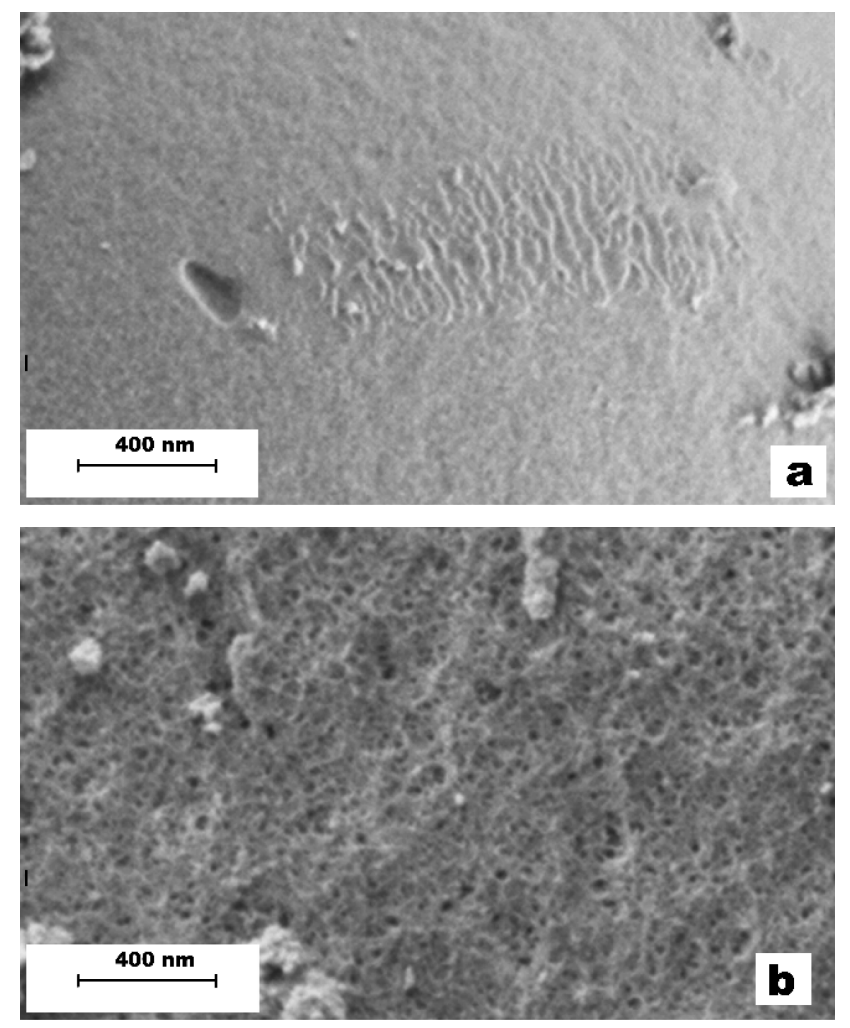

Fig. 1. SEM images of samples $4 \mathrm{~V}\left(\mathrm{H}_{2} \mathrm{O}\right)$ (a), and $1 \mathrm{~V}\left(\mathrm{H}_{2} \mathrm{O}\right)(\mathrm{b})$. structure of the glasses $[11,12]$. Therefore, low $Q$ range of SANS data was fitted using fractal model.
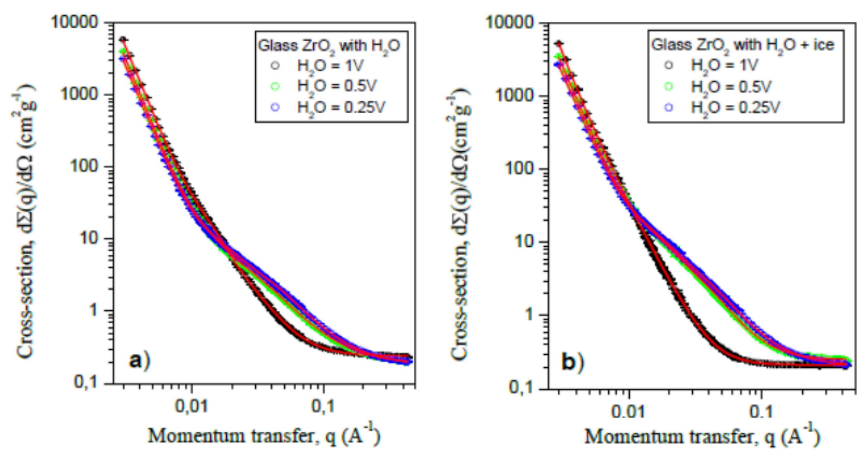

Fig. 2. Scattering from samples synthesized at $20{ }^{\circ} \mathrm{C}$ (a) and $0{ }^{\circ} \mathrm{C}$ (b) obtained by KWS- 1 and KWS-3 instruments.

For samples with lower water content ( $1 \mathrm{~V}$ and $2 \mathrm{~V})$, SANS data were fitted using a combination of the massfractal model and a spherical particles model with narrow log-normal size distribution. SANS data for samples with higher water content $(4 \mathrm{~V})$ did not show a presence of nanoporosity. Therefore those curves were fitted using just fractal models. Mean radii $\left(R_{\mathrm{s}}\right)$ and fractal dimensions ( $D_{\mathrm{f}}$, where $D_{\mathrm{f}}=D$ for mass fractals) obtained from the fit are summarized in the Table.

Fitted parameters from SANS data.

TABLE

\begin{tabular}{c|c|c|c|c|c|c}
\hline \hline $\mathrm{H}_{2} \mathrm{O}: \mathrm{Zr}$ & \multicolumn{2}{|c|}{14 mass \%: $10.58 \mathrm{~mol} \%$} & \multicolumn{2}{c|}{7.5 mass \% $5.29 \mathrm{~mol} \%$} & 4 mass \%:2.65 mol \% \\
\hline temperature of sol-gel processing & $20{ }^{\circ} \mathrm{C}$ & $0{ }^{\circ} \mathrm{C}$ & $20{ }^{\circ} \mathrm{C}$ & $0{ }^{\circ} \mathrm{C}$ & $20{ }^{\circ} \mathrm{C}$ & $0{ }^{\circ} \mathrm{C}$ \\
sample name & $4 \mathrm{~V}\left(\mathrm{H}_{2} \mathrm{O}\right)$ & $4 \mathrm{~V}\left(\mathrm{H}_{2} \mathrm{O}\right)$-ice & $2 \mathrm{~V}\left(\mathrm{H}_{2} \mathrm{O}\right)$ & $2 \mathrm{~V}\left(\mathrm{H}_{2} \mathrm{O}\right)$-ice & $1 \mathrm{~V}\left(\mathrm{H}_{2} \mathrm{O}\right)$ & $1 \mathrm{~V}\left(\mathrm{H}_{2} \mathrm{O}\right)-\mathrm{ice}$ \\
$R_{\mathrm{s}}[\mathrm{nm}]$ & - & - & 12.0 & 9.9 & 9.2 & 9.5 \\
$D_{\mathrm{f}}$ & $2.73 \pm 0.03$ & $3.34 \pm 0.03\left(D_{\mathrm{s}}=2.66\right)$ & $2.02 \pm 0.03$ & $2.74 \pm 0.03$ & $2.19 \pm 0.03$ & $2.39 \pm 0.03$
\end{tabular}

Decrease in the temperature of sol-gel process leads to an increase in fractal dimensions. In other words, the structure of corresponding samples is more compact [13]. Obtained values of $D_{\mathrm{f}}>2$ are typical for fractal aggregates produced under slow reaction conditions [14], so called reaction-limited cluster aggregation (RLCA). Scattering for the sample $4 \mathrm{~V}\left(\mathrm{H}_{2} \mathrm{O}\right)$-ice corresponds to surface fractal with the fractal dimension [11] $D_{\mathrm{s}}=(6-D)=(6-3.34)=2.66$. Specific surface obtained by the Brunauer-Emmett-Teller (BET) measurements is inversely dependent on $\mathrm{H}_{2} \mathrm{O}$ content (see Fig. 3) and it almost approaches zero for samples $4 \mathrm{~V}$. Such porosity behavior obtained by BET well correlates with SANS results, since nanopores observed using SANS in samples $1 \mathrm{~V}$ and $2 \mathrm{~V}$ contribute the most to the total porosity.

\section{Conclusions}

Zirconia-based bulk glasses were prepared for the first time using sol-gel method. These materials possess high microstructure dependence on parameters of preparation procedure. The specific surface increases with decreasing

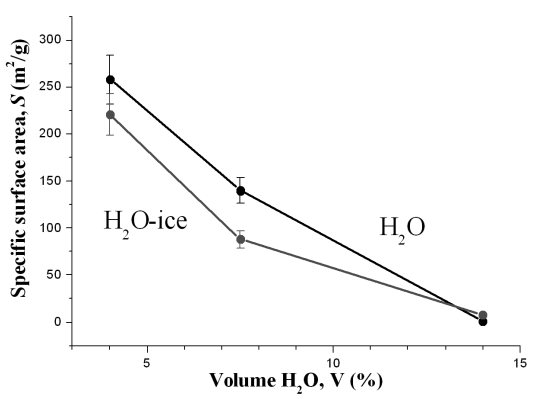

Fig. 3. Specific surface of pores obtained by BET method.

water-to-zirconium ratio in initial mixtures due to formation of nanosized pores detected by SANS. This type of porosity is nearly absent in zirconia glasses prepared from reaction mixtures with higher water-to-zirconium ratio. Large inhomogeneities in studied glasses have fractal self-similar nature. The fractal dimension obtained from SANS increases with decrease of the synthesis temperature, i.e. microstructure of the glasses synthesized at lower temperature is more compact. 


\section{Acknowledgments}

This research was supported by the Czech Science Foundation under the grant No. 14-36566G. Measurements at MAUD were carried out at the CANAM infrastructure of the NPI ASCR Rež supported through MŠMT project No. LM2011019. SANS experiments were performed at the KWS-1 and KWS-3 instruments operated by JCNS.

\section{References}

[1] L. Sun, J. Yao, C. Liu, C. Liao, C. Yan, J. Lumin 87-89, 447 (2000).

[2] A. Gaudon, F. Lallet, A. Boulle, A. Lecomte, B. Soulestin, R. Guinebretière, A. Dauger, J. NonCryst. Solids 352, 2152 (2006).

[3] V. Gerold, G. Kostorz, J. Appl. Crystallogr. 11, 376 (1978).

[4] V.K. Ivanov, G.P. Kopitsa, A.Ye. Baranchikov, M. Sharp, K. Pranzas, S.V. Grigoriev, Russ. J. Inorg. Chem. 54, 2091 (2009).

[5] V.K. Ivanov, G.P. Kopitsa, O.S. Ivanova, A.Ye. Baranchikov, K. Pranzas, S.V. Grigoriev, J. Phys. Chem. Solids 75, 296 (2014).

[6] V.K. Ivanov, A.Ye. Baranchikov, G.P. Kopitsa, S.A. Lermontov, L.L. Yurkova, N.N. Gubanova, O.S. Ivanova, A.S. Lermontov, M.N. Rumyantseva, L.P. Vasilyeva, M. Sharp, P.K. Pranzas, Yu.D. Tretyakov, J. Solid State Chem. 198, 496 (2013).
[7] N.N. Gubanova, A.Ye. Baranchikov, G.P. Kopitsa, in: Proc. 17th Int. Sol-Gel Conf., Madrid (Spain), 2013, p. 235.

[8] P. Mikula, P. Lukas, F. Eichhorn, J. Appl. Crystallogr. 21, 33 (1988).

[9] P. Strunz, J. Šaroun, P. Mikula, P. Lukáš, F. Eichhorn, J. Appl. Crystallogr. 30, 844 (1997).

[10] A. Radulescu, E. Kentzinger, J. Stellbrink, L. Dohmen, B. Alefeld, U. Rücker, M. Heiderich, D. Schwahn, T. Brückel, D. Richter, Neutron News 16, 18 (2005).

[11] J.F. Gouyet, Physics and Fractal Structures, Springer, Amsterdam 1996.

[12] J. Teixeira, in: On Growth and Form - Fractal and Non-Fractal Pattern in Physics, Eds. H.E. Stanley, N. Ostrovsky, Martinus Nijloff Publ., Boston 1986, p. 145.

[13] M.Y. Lin, H.M. Lindsay, D.A. Weitz, R.C. Ball, R. Klein, P. Meakin, Nature 339, 360 (1989).

[14] D.A. Weitz, M.Y. Lin, J.S. Huang, T.A. Witten, S.K. Sinsha, J.S. Gertner, C. Ball, in: Scaling Phenomena in Disordered Systems, Eds. R. Pynn, A. Skjeltorp, Springer Science \& Business Media, New York 1991, p. 171. 